\title{
POLÍTICA EDUCACIONAL PAULISTA: ANÁLISE DA GESTÃO DO PMDB*
}

Cleiton De Oliveira ${ }^{* *}$

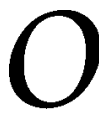

s cursos de pós-graduação em Educação, em pouco mais de três décadas, têm contribuído para a titulação de professores universitários, formando pesquisadores e possibilitando um grande desenvolvimento na produção de conhecimentos. $\mathrm{Na}$ área de Política Educacional, na qual se inscreve o texto, objeto desta resenha, o desenvolvimento foi considerável, concorrendo para o acúmulo de conhecimentos que subsidiam a formação da agenda das políticas para a área, a formulação de programas, a implementação, o monitoramento e a avaliação das mesmas.

0 trabalho em análise é fruto da tese de doutorado, defendida por Zacarias Pereira Borges, na Faculdade de Educação da UNICAMP, em 2002, sob a orientação do Prof. Dr. José Roberto Heloani.

O Prof. Zacarias tem uma longa experiência na rede estadual paulista de ensino básico, tendo atuado como professor, diretor de escola, supervisor e delegado de ensino; esta experiência, por um lado, lhe possibilitou conhecer profundamente a rede escolar; por outro lado, a mesma poderia prejudicar sua análise pelo envolvimento e eventual visão unilateral do período; porém, o autor soube distanciar-se o suficiente, realizando sua análise à luz de documentos e de uma bibliografia adequada.

A pesquisa "analisa a política educacional desenvolvida pela Secretaria de Estado da Educação do Estado de São Paulo no período de 15 de março de 1983 a 31 de dezembro de 1994 (...) o período estudado foi comandado por três governadores pertencentes ao mes-

* Resenha do livro Política e educação: análise de uma perspectiva partidária, de Zacarias Pereira Borges (Campinas: Gráfica da FE/ unicamp e Hortograph, 2002. 294p.).

* Professor do Programa de Pós-graduação em Educação da Universidade Metodista de Piracicaba (unimeP). E-mail: cleolive@ unimep.br. 
mo partido político: 0 PMDB" (p. 3). A investigação restringe-se à educação básica, nível sob responsabilidade da citada Secretaria, procurando "entender a interface político-pedagógica das ações desenvolvidas pelos nove secretários de estado da educação" que atuaram no período, "confrontando essas ações com o programa do partido que assumiu o poder (PMDB), considerando a chamada 'Proposta Montoro' para a educação em São Paulo" (p. 4).

A partir do programa do PMD B e da Proposta Montoro para a educação, o autor elegeu categorias de análise e, através destas lentes, examinou os programas e projetos desenvolvidos no período. Assim, foram definidas as seguintes categorias: política e gestão, compreendendo a descentralização e a participação; atendimento à demanda escolar, compreendendo a pré-escola, o ensino fundamental e o médio; valorização dos profissionais da educação, considerando os níveis de atuação citados; controle das instituições privadas de educação; e melhoria da qualidade do ensino, a partir da reformulação de conteúdos, métodos e objetivos da educação.

0 trabalho é composto por cinco capítulos: o primeiro se detém na análise do conceito e funções dos partidos políticos, apresentando também uma retrospectiva destas agremiações desde 0 império até o período estudado; o segundo é dedicado ao PMDB, analisando suas propostas e recomendações para a educação, bem como à Proposta Montoro para a educação; os três capítulos seguintes são dedicados à apresentação e análise das ações desenvolvidas na área do ensino em cada uma das gestões estaduais.

A gestão do governador André Franco Montoro (15/ 03/ 1983 a 15/ 03/ 1987) foi analisada considerando a atuação de três secretários estaduais de Educação: Paulo de Tarso Santos (15/ 03/ 1983 a 28/ 05/ 1984), Paulo Renato Costa Souza (29/05/ 1984 a 19/ 04/ 1986) e José Aristodemo Pinotti (16/ 05/ 1986 a 15/ 03/ 1987); no interregno entre os dois últimos, respondeu pela pasta, interinamente, Luiz Carlos Bresser Pereira, acumulando esta função com a de secretário de governo.

A segunda gestão analisada foi a de O restes Q uércia (15/03/ 1987 a 15/ 03/ 1991), respondendo pela pasta da Educação: Chopin Tavares de Lima (15/ 03/ 1987 a 03/ 08/ 1989), Wagner G onçalves Rossi (04/ 08/ 1989 a 10/ 01/ 1990), José G oldemberg (11/ 01 a 06/ 04/ 1990) e Carlos Estevam Martins (07/ 04/ 1990 a 15/ 03/ 1991). 
Luiz Antonio Fleury Filho (15/ 03/ 1991 a 31/ 12/ 1994) foi o terceiro governador do período, tendo como secretários estaduais de Educação: Fernando G omes de Morais (15/ 03/ 1991 a 03/ 09/ 1993) e, novamente encerrando mandato, Carlos Estevam Martins (10/ 09/ 1993 a 31/ 12/ 1994); Luis Patrício Cintra do Prado Filho atuou interinamente entre duas gestões.

O autor realizou uma minuciosa pesquisa na legislação estadual do período, indicando que as "fontes utilizadas foram essencialmente 31 leis, 74 decretos dos governadores, 117 resoluções dos secretários de educação, além de diversas portarias dos coordenadores, comunicados, deliberações e pareceres do Conselho Estadual de Educação" (p. 6). Valeu-se também de outros materiais de trabalho para reuniões e seminários promovidos pela Secretaria de Estado da Educação. Analisou, ainda, a tramitação de vários documentos legais, discutindo a natureza dos mesmos e apontando, quando foi o caso, atos que tiveram tratamento diverso do convencional. Em várias situações o autor rompeu com o período estudado: seja antecedendo no tempo, procurando desvelar as raízes das questões, seja indo além, procurando esclarecer 0 leitor sobre o destino do programa/ projeto.

Em relação a cada secretário de estado da Educação, o autor preocupou-se em analisar não só os atos legais, como outros aspectos que caracterizaram cada gestão. Assim, estão descritos os atos de posse, são citados trechos dos discursos, são indicados os principais assessores que não pertenciam ao quadro da Secretaria, são descritos os modos de condução dos encontros dos titulares da pasta com os diretores regionais e delegados de ensino. Ainda, são indicados os cargos ou funções que esses titulares desempenharam anterior e posteriormente ao período em que responderam pela pasta da Educação, bem como as razões que levaram à substituição dos mesmos.

0 texto contabiliza as greves ocorridas no período, número de dias parados, as razões que as provocaram, estando entre todas elas a questão dos baixos salários e os resultados obtidos. Em dois dos casos estudados, a troca de secretários deu-se após períodos de greve.

0 autor elaborou quadros elucidativos, facilitando a compreensão do leitor em relação à temática. Para a gestão de cada secretário foi elaborado um quadro contendo os dispositivos legais das ações empreendidas, as datas dos mesmos e suas ementas. O utros três quadros foram elaborados, sendo um para cada governo, com colunas corres- 
pondentes a cada secretário e às respectivas ações propostas, de acordo com as categorias de análise levantadas.

É interessante observar as datas em que determinadas medidas legais são publicadas. Algumas ocorrem em período de férias ou muito próximo a elas, evitando assim a reação do magistério; este é o caso, por exemplo, da criação do Ciclo Básico em 28/ 12/ 1983 (experiência anterior, de curta duração, havia ocorrido na segunda metade dos anos de 1960). O utras medidas que demandaram providências das escolas e/ ou de prefeituras municipais foram tomadas, igualmente, em épocas inoportunas; dentre outros, temos os seguintes casos: alterações curriculares (07/ 01/ 1985), estabelecimento da jornada única docente e discente no Ciclo Básico (21/ 01/ 1985), alterações no preenchimento de fichas de avaliação dos alunos (29/ 01/ 1985), criação do PROFIC (07/ 07/ 1986), criação do CEFAM (13/ 01/ 1988), estabelecimento de convênio para transporte de alunos com 0 ano já em andamento (23/ 03/ 1984 e 04/ 03/ 1991).

O s dados do texto permitem observar que determinados programas permaneceram ao longo das três gestões, tal é o caso da municipalização da merenda escolar; ao mesmo tempo, é interessante verificar que há programas que recebem recursos e empenho para que sejam aceitos na gestão do secretário que os criou. Porém, ao longo do tempo, sem o entusiasmo dos sucessores e concorrendo com as criações destes, vão morrendo por inanição. Este é o caso, por exemplo do PROFIC.

Decorre do exposto que os secretários procuram marcar suas gestões com criações ou, quando não, por recriações de programas, relegando a um segundo plano o trabalho desenvolvido na rede de ensino. Estes foram os casos do PROFIC e da Escola Padrão (embora este tenha ocorrido em governo posterior ao estudado).

No período analisado, a descentralização do ensino deu-se em relação à Fundação do D esenvolvimento da Educação (FDE), aos municípios e à Associação de Pais e Mestres (APM) das escolas.

A FDE encarregou-se de várias atividades, tanto em relação a recursos materiais quanto a aspectos pedagógicos. Esta entidade, conforme 0 programa, interagiu com a própria rede estadual, com prefeituras municipais e com as APM. A importância desta Fundação e, consequentemente, seu rol de atividades, variou conforme o secretário. 
O s municípios, por intermédio de convênios, se encarregaram de programas direcionados à rede estadual. Assim, dentre outros, foram realizados convênios em relação à merenda, transporte, construções e pessoal de apoio. É de se registrar que nem todos os municípios participaram dos programas. A pesar do empenho em relação à municipalização do magistério e de escolas, observou-se que apenas o secretário Carlos Estevam Martins, em duas gestões, apresentou propostas nesta direção, sem obter resultados significativos. Por outro lado, a municipalização do ensino pré-escolar ocorreu sem maiores problemas: à medida que os municípios ampliavam seu atendimento, a rede estadual suprimia suas classes.

As Associações de Pais e Mestres participaram de programas descentralizados em relação à manutenção de prédios e na contratação de pessoal para serviços gerais. É de se registrar que a grande maioria das escolas não participou destes programas.

As medidas desconcentradoras deram-se em relação à transformação das delegacias de ensino em unidades de despesas e na criação das oficinas pedagógicas. $\mathrm{O}$ autor teceu interessantes comentários em relação a estas atividades, demonstrando o quanto elas caminham em direção a uma maior participação. D eteve-se também na análise da Escola-Padrão, a qual, por diferenciar-se da rede convencional, caminhou em direção a uma maior autonomia.

Conclui o autor afirmando que determinados programas, como o PROFIC, bem como a criação da FDE, não estavam previstos na proposta partidária. Afirma que no período estudado "descentralizou-se pouco, desconcentrou-se um pouco mais e a participação anunciada limitou-se à participação do dever de opinar". Em nenhum dos governos houve preocupação com o cumprimento do programa partidário, "mesmo pressupondo as alterações de rota que pudessem ser necessárias, ficando realmente a educação em São Paulo ao sabor dos conceitos que dela cada Secretário fizesse" (p. 284).

Recomenda-se a leitura do trabalho em tela considerando o rigoroso levantamento da legislação, o minucioso mapeamento das atividades realizadas pela Secretaria de Estado da Educação no período e pela análise realizada apoiada em farta documentação.

Enfim, o texto reflete o domínio que o autor tem sobre a temática. Por isso tudo, este trabalho certamente será uma fonte segura para os que forem analisar o ensino paulista no período. 